\title{
If I Could But Choose Again, I Would Choose Wisely: A Psychoanalytic Approach To Mark Twain's The Five Boons of Life
}

\author{
Ali Baram Mohammed \\ Department of Computer Science, Darbandikhan Technical Institute, Sulaimani Polytechnic University, Sulaimani, Kurdistan \\ Region - F.R. Iraq
}

\begin{abstract}
There are myriads of wants, wishes, and desires in the minds of human beings. However, the fulfillment of these needs is not always possible, for there are some internal and external factors governing the satisfaction of each desire. Before gratifying any needs and deciding whether or not to fulfill any request, it is crucial to examine the nature of this specific demand and consider the consequences that might eventually be brought about. The paper aims to represent the theme of repentance in The Five Boons of Life, which emerges from making wrong choices in life and the bitter consequences that follow. Further, it claims that Freud's psychoanalytic theories can be applied to Mark Twain's short story, The Five Boons of Life. The study is important as it may give some insights about where the regret comes from and how the human psyche works.
\end{abstract}

Index Terms - Decision, Desires, Freud, Mark Twain, Psychoanalysis, The five boons of life.

\section{INTRODUCTION}

The Five Boons of Life is a fable, which contains a sequence of interactions between a young man and a fairy. The fairy brings a basket full of gifts for the young man to choose from. The gifts or the boons of life are Fame, Love, Riches, Pleasure and Death. The fairy propounds that the man can only choose one of the gifts and it; therefore, is significant that he chooses wisely (Twain, 1885). Every time, the man follows his desires and picks the wrong boon, which consequently brings about desolation and regret. He is blinded by material and worldly possessions and for the sake of temporary pleasures, he eventually loses real and everlasting happiness, which is portrayed as death in the story (Daniels, 2009). This story is of massive significance for us because it concentrates upon the fact that life is very precious and we have to be cautious not to waste it in chasing minor things and fulfilling the short-lived desires of our hearts. The story further focuses on the importance of making wise decisions in life, as they inevitably determine one's final destination.

Nevertheless, Freud in his theories of psychoanalysis claims that there are three main parts in the human psyche or personality that determine the decisions and/or the choices of the individuals. These three parts include the id (physical pleasure and desire), the ego (reality and socially acceptable behavior), and the superego (morals and right/wrong judgments), each of which is driven by different principles and functions accordingly (Sibi, 2020). However, Freud asserts that these three parts of personality have to be combined and balanced together to attain the multifarious behavior of human beings. Since each of these agencies yearns for different things, in turn, they require diverse decisions and choices. (Lapsley and Stey, 2011). These three parts of the human psyche are thus responsible for most of the decisions humans make on daily basis. The man in Twain's story invariably fails to make the right choice as he seems to be more driven by his id rather than ego and/or superego.

Much literature has been dedicated to critically analyze The Five Boons of Life. Some of them are only concerned with the genre and figurative language of the story. These critics seem to engage with the aesthetic features of the story and celebrate the highly metaphorical language of the story, which is quite unprecedented to the poetic language of Mark Twain (Chavez, 2020). Mark Twain has acquainted his readers with simple and vernacular language in his works. He mostly reflects the everyday speech of the people in his works. For instance, his well-reputed novel, The Adventures of Huckleberry Finn (1885) has been written throughout in vernacular language and it contains more than two hundred instances of the "nigger" word. "Niggers is always talking about witches in the dark by the kitchen fire; but whenever one was talking and letting on to know all about such things, Jim would happen in and say, "Hm! What you know "bout witches?" and that nigger was corked up and had to take a back seat" (Twain, 1885).

However, the language of The Five Boons of Life is quite figurative and rich in metaphors and/or allegories. For instance, in the first chapter "the morning of life", the author metaphorically refers to the beginning of life, the time when humans are young, active and have myriads of desires or aims

Journal of University of Human Development

Volume 7 No. 4(2021); DOI: 10.21928/juhd.v7n4y2021.pp11-15

Regular research paper: Received 20 June 2021; Accepted 22 July 2021; Published 27 September 2021

Corresponding author's e-mail: ali.mohammed@spu.edu.iq

Copyright (02021 Ali Baram Mohammed. This is an open access article distributed under the Creative Commons Attribution License (CC BY-

NC-ND 4.0) 
to achieve. Another example of using metaphor is where the writer says: "And last of all came pity, which is the funeral of fame" (Twain, 1885). He uses pity to metaphorically represent the end of fame. Personification is also used in the story when the fairy advises the young man to choose warily as time is flying.

Other scholars seem to focus solely on the literary movement it represents. Accordingly, they attempt to describe it by placing it within its literary movement, which is realism. For this school of thought, The Five Boons of Life is a flawless representation of realism, for it repudiates the essential ideas of idealism and mainly focuses on everyday problems of life. The themes of the realism movement are; hunger, exhaustion of man, poverty, the inevitable challenges of this life and the idea of not reaching a state of peacefulness and serenity in this life (Zarnigor, 2019). These concepts are well depicted in the story, where the young man chooses all the earthly pleasures of life and yet he is not satisfied. After every choice he makes, he falls into a state of anxiety and depression. At the end of the story, it is exposed to the man that the only valuable and worth choosing boon was death, for it is the only remedy for human problems and sufferings in this world.

Although some scholars have studied the psychological aspects of the story in general, to the researcher's knowledge, not any scholarly article seems to have tackled the story in terms of Freud's psychoanalytic theories of the mind. For instance, why the man makes these choices in the first place? Or why he cannot stop himself from following the worldly pleasures and picking the wrong choices?

This paper; therefore, claims that Freud's theories of psychoanalysis can be applied to this story and the constant battle between the id (human desires and pleasure based principles) and the superego (human reason and morality principles) is conspicuously reflected in the story. The man himself stands for the id whereas the fairy is his superego. The ego (reality driven principle) can be imagined in the real accidents that happen to the man in the story after each choice he makes. To prove the aforementioned statement, the three instincts of personality will be thoroughly considered in this paper, each chapter of the story will be critically and meticulously studied and ultimately a connection between Freud's theories of psychoanalysis and the events of the story will be drawn.

\section{FREUD'S PSYCHOANALYTIC THEORIES (ID, EGO AND SUPEREGO)}

Sigmund Freud, who is considered the founder of modern psychology, claims that the unconscious mind governs the conscious mind (Sibi, 2020). There are, moreover different layers in the human mind which are: unconscious, preconscious, and conscious. These layers have specific devices, which are the id, ego, and superego. Freud compares the human mind to an iceberg. On the tip of the iceberg and occupying only a tiny space is the conscious mind, which is fully aware of the present feelings, thoughts, and perceptions. Under the conscious mind, Freud claims, is the preconscious, which too occupies small space and functions like a memory to serve the conscious mind. However, these two parts of the mind are far less important and functional than the unconscious mind, which is the foundation of the iceberg and accounts for all the things that are not easily retrievable in the conscious mind, such as instincts, dreams, drives, feelings, etc. Hence, the unconscious is the most important part of personality and functions like storage for wishes and desires of human beings (ibid).

\section{THE ID}

The Id is the unorganized part of the human psyche that completely operates in the unconscious mind and it is the only part of the mind that is present since birth. According to Freud, Id is the main component of the human psyche, for it provides all the psychic energy. The Id is a pleasure-driven principle and yearns for immediate fulfillment of its wishes and desires, otherwise, it will lead to a state of depression and anxiety. The pleasure principles of the Id seek instantaneous fulfillment of the desires, wishes, and human wants. However, the gratification of these wishes is not always immediately possible. Consequently, a psychological tension is mostly brought about that requires to be somewhat discharged. The Id itself attempts to solve this tension through, what Freud calls, primary process. The primary process is a process, through which the Id attempts to create a mental image, as a substitute for the dangerous or impossible desires of the Id, to subdue the urge. This imagination or mental production of the desired objects and wishes is essential in relieving the anxiety and/or psychological tension (Siegfried, 2014).

A very conspicuous example of this process is daydreaming. Freud argues that the essence of daydreaming is to relive pshychological tension. It initiates from a mental image for the things we desperately want. The mental image functions as a substitution for these things and gives psychological relief, even though temporary. The same idea is true for other sexual impulses in human beings. The desire for sexual intercourse is very powerful in humans and, as Freud suggests, it is almost always present. On the other hand, since it is not always possible to gratify these sexual yearnings, humans resort to masturbation (Zucker, 1979).

\section{THE EGO}

According to Freud, the Ego develops from the Id and it is the component of the psyche that ensures that the impulses of the Id can be expressed in a manner acceptable in the real world. The Ego functions in the conscious mind, but also plays a role in the unconscious. It is the component of personality that is responsible for dealing with reality. The Ego operates based on the reality principle, which strives to satisfy the Id's desires in realistic and socially appropriate ways. Freud compared the Id to a horse and the Ego to the horse rider. The horse provides the power and motion, while the rider provides direction and guidance (Zucker, 1979). Without its rider, the horse may 
simply wander wherever it wishes. The rider gives the horse directions and commands in order to control the direction and the moves of the horse.

Furthermore, Freud defines the Ego as "a coherent organization of mental processes" (Siegfried, 2014). The Ego is, thus the section of the psyche that controls all the complex processes in the mind, such as, controlling the ways the Id's wishes and desires are discharged in reality. It functions as authority over the Id's impulses and censors the dreams even when the person is sleeping. It is through this censorship upon one's dreams that the Ego's role in the unconscious is manifested.

The Ego represses many aspects of mental thinking, not only from the conscious but also from other manifested activities in the unconscious mind. The Ego can distinguish between reality and fantasy; what can be plausibly obtained and what has to be avoided. It thus tries to reorganize human thoughts and reshape their behaviors. Additionally, the Ego can be considered as common sense or the reason of humans that attempt to make sense of the world. The Ego's fundamental role is to serve three masters, which are; outside world, the Id, the Superego, and keep a balance among them.

\section{THE SUPEREGO}

According to Freud, the Superego begins to emerge at around age five and it holds the internalized moral standards and ideals that we acquire from our parents and society (our sense of right and wrong). The Superego tries to perfect and civilize our behavior. It works to suppress all unacceptable urges of the Id and struggles to make the Ego act upon idealistic standards rather than upon realistic principles. The Superego is present in the conscious, preconscious, and unconscious mind. As early as the child is about five years of age, he or she learns their sense of good and bad through their parent's reactions to their behavior. Since there is a reward for the good and a punishment for the bad behavior, the child strives to do and follow what is good and ideal. Through these small and local treatments and considerations, the child develops their sense of internalization of moral or parental standards(Zucker,1979).

As the child grows into adulthood, the Superego too continues to develop and expand its horizon. This time, instead of only recognizing with their parents and coping with their rules and advice, the Superego attempts to cope with the standards and morals of a larger community, the outside world. The young adult in this stage of life commences to have more role models in the society and tries to imitate as many of the admired models as possible. As their boundaries of right or wrong are pushed further, they inevitably have to oppress and resist much of their wishes and desires. Particularly those, which are not in accordance with the moral principles in their mind. It is also in this stage that the feeling of guilt, and regret emerges within the psyche of the individuals. Anytime they violate any of the standards of their Superego, they will fall into a state of anxiety and agitation (Norman, 2016). Therefore, the Superego is not satisfied except when the person reaches perfection. It contradicts with the impulses of Id, and stands against the fantasies, desires and every other want of the Id, as they are not socially and morally acceptable.

\section{THE INTERACTION OF THE ID, EGO, AND/OR SUPEREGO}

When talking about the id, the ego, and the superego, it is important to remember that these are not three separate entities with clearly defined boundaries. These aspects are dynamic and always interacting to influence an individual's overall personality and behavior. However, as previously mentioned in the paper, the Superego always contradicts the Id and this disputation brings about a conflict between them. In this stage, it is the responsibility of the Ego to intervene and mediate between the two. Nevertheless, puzzled among three different forces, which are the anxiety of the actual world, moral anxiety created because of Superego, and internal anxiety as a result of the too-powerful desires and demands of the Id, the Ego sometimes breaks out in anxiety and fails in bringing about harmony. To discharge this anxiety and reduce the tension, the Ego resorts to what Freud calls Defense Mechanisms.

Among the Defense Mechanisms, Sublimation in particular is quite prevalent and functions effectively (Dumitrescu, 2020).

Sublimation is the conscious transformation of unwanted impulses and/or desires into less harmful activities. Everyone experiences unwanted desires and wishes at some point in their lives and as they cannot gratify these wishes in these given times, they would have to search for a solution for them (Ken, 2009). These sudden requirements, which usually emerge from the Id, are not socially acceptable, therefore the Ego employs sublimation to delay or consciously convert these impulses into socially accepted behaviors. Freud asserts that sublimation is a trait of maturity. It occurs when one gives up their wishes because of the cultural and societal norms and spends the energy in attaining more important achievements (Siegfried).

To conclude, it is through analyzing these components of the human psyche and their functions that we are able to understand the overall behavior of humans both culturally and individually. If we study these three drives of the mind, the Id, Ego, and Superego and interpret their functions appropriately, we will better understand why certain individuals behave in certain ways. They will also help us understand our behaviors and figure out the motifs of our actions. To better understand the functions and positions of each of these components of the mind, in the next section of the paper, these three parts of the mind will be examined in Twain's The Five Boons of Life.

\section{THE FIVE BOONS OF LIFE: A PSYCHOANALYTIC STUDY}

The Five Boons of Life consists of five chapters, which metaphorically represent various stages of life. Each of the chapters poses a new trial and difficulty for the young man as he has to make the right choice to satisfy his desires on one hand and find peace in his life, on the other. However, these two aims do not seem to be attained at the same time. He cannot be 
following his Id and obtaining the approval of the Superego at the same time. He is blinded by the too powerful desires of his Id; therefore, cannot seem to take advantage of what the fairy invariably tells him. The fairy stands for his Superego, as mentioned previously in the claim of the paper.

In the first chapter, the fairy offers five gifts, which are: Fame, Love, Riches, Pleasure and Death. She also warns him to "choose wisely". This notion of making the right choice is the idea of learning to internalize parental standards of good and bad, which is the function of the Superego and emerges when the person is about five years of age. In this stage of the story, the man is young and as he seems to be more driven by his pleasure principles, without any consideration he picks the boon of "pleasure". "There is no need to consider; and he chose Pleasure" (Twain, 1885). This immediate gratification of the impulse is inarguably the function and the superiority of the Id over the Superego, which inevitably brings about shame, sadness and repentance. As Freud claims, the instantaneous satisfaction of the Id's urges, without considering the Ego and Superego is always short-lived and leads to a state of depression and pain (Cherry, 2020).

This fact is evidently reflected in the story where all the pleasures in the world were only temporary and did not come up with the young man's expectations. "But each in its turn was short-lived and disappointing, vain and empty; and each, departing, mocked him." (Twain, 1885). Additionally, Pleasure is the first choice of the man, which is yet another confirmation of Freud's theories that most of the impulses of humans are governed and generated by pleasure principles of the Id (Cherry,2020).

In the second chapter, the fairy returns with her basket and offering four of the remaining gifts to the man. The youth has now grown into a man and considers long before choosing the gift. However, as he is still governed by the impulses of his Id, his considerations are of no avail and yet again he ignores the fairy's caveat and opts for the gratification of another temporary wish. "The man considered long, then chose Love; and did not mark the tears that rose in the fairy's eyes." (Twain, 1885). The fairy is crying, this very sentence confirms Freud's theories of the tension between the Id and the Superego.

Each of these two drives relentlessly fights to win the battle and overcome the other. The Id and the Superego are quite opposite and the triumph of one, Freud states leads to the anxiety and desperation in the other, it is the function of the Ego to intervene in such tensions and mediate between these two drives (Liang, 2011). However, in this instance of the story, the Id wins the conflict again and the Superego causes destruction and desperation in the psyche of the man. "Desolation after desolation has swept over me; for each hour of happiness the treacherous trader, Love, as sold me I have paid a thousand hours of grief. Out of my heart of hearts I curse him." Although we often tend to regret the decisions made based on the impulses of the Id, this recognition and repentance is mostly realized when it is too late.

In chapters three and four, the fairy comes to the man again and warns him that there still is some time to use his wisdom and make the right choice. The remaining gifts in the basket are;
Fame, Wealth and Death. Regrettably, and since he is still governed by the instincts of his Id, the man only considers the present situations and overlooks the long-term consequences of his decisions, and chooses fame and wealth, respectively. Freud stresses that disobeying the impulses of the Id and following the rules of the Superego will ultimately result in a state of being proud, valuable and accomplished. While disobeying the Superego and going with the demands of the Id leads to a feeling of guilt and long-term psychological stress (Cherry, 2020). The idea of short-lived satisfaction is also repeated here. The realization of the desires of the Id might have temporary joys, but in turn, bring about regret and sorrow. Consequently, the fame changes to pity: "And last of all came pity, which is the funeral of fame. Oh, the bitterness and misery of renown!" (Twain, 1885). The desperation and feeling of guilt that arose because of the Id are well presented and felt here.

The desperate realization of having spent one's life in vain and the bitter feeling of guilt that one falls into owing to disobeying the Superego is very wisely embodied in the story. The man sights for having disobeyed the fairy (superego) for so long: "Curse all the world's gifts, for mockeries and gilded lies! And miscalled, everyone. They are not gifts, but merely lendings. Pleasure, Love, Fame, Riches: they are but temporary disguises for lasting realities -- Pain, Grief, Shame, Poverty."(Twain, 1885). The man here admits that pleasure meant pain, love only brought grief, fame resulted in shame and eventually, riches caused poverty.

However, this awakening comes when it is too late and it is of no avail now. Death, which in reality resembles life (as the gifts are described in reverse in the story, one can deduce that death stands for life), and the moral choices that one ought to make based on the Superego drive, is no longer available. When the man asks for Death in the final chapter the fairy replies: "I gave it to a mother's pet, a little child. It was ignorant, but trusted me, asking me to choose for it. You did not ask me to choose". This last sentence is very important, the fairy (superego) says you did not consider my opinion and instead chose to follow the desires (id). And therefore you should live all your life in desolation and insult of old age.

Twain's The Five Boons of Life is a fascinating insight into the significance of life and its priorities. Although it does not have a joyful ending, yet there is a very profound lesson behind the fable. The story stresses the importance of wise choices and not squandering one's life away. Analyzing the Five Boons of Life is like asking the ubiquitous question, "if you were granted one wish, what would that be?". While the answer for that question differs from an individual to another, it also changes as one grows older and attains more wisdom (Swati, 2020). As we are young, we tend to think of temporary happiness and fulfillment of our momentary desires. However, the moment these wishes are attained, they lose their value in our perception and we either regret asking for them or want to make another wish. Thus, there is no end to desire, obtaining one desire is inevitably followed by the craving for the other and then another. This long quest of attaining myriads of temporary desires of our hearts inevitably leaves us unaware of the permanent and more valuable goals of our lives, which is 
seeking the ultimate contentment of God, Almighty. Consequently, we lead ourselves to a state of depression and irreversible repentance (ibid). Therefore, it is extremely significant for human beings not to allow their desires to gain advantage over them and learn how to draw limits for their wishes.

\section{CONCLUSION}

Freud claims that any imbalance among the drives of the mind; the Id, the Ego, and the Superego, will inevitably lead to a state of anxiety and depression. In our story, The Five Boons of Life, the man always attempted to gratify the wishes and desires of his Id and did not seem to consider what the fairy, his Superego has been constantly telling him. Therefore, it is not surprising that he eventually has fallen into this state of regret and selfguilt. Hence, Freud's concepts of Psychoanalysis can be evidently applied to the story. The more one feeds the desires and impulses of the Id, the more they suffer the inevitable desolation in the end. Analyzing The Five Boons of Life through Freudian concepts of psychoanalysis helps in understanding the factors influencing human beings' decisions in life.

\section{REFERENCES}

Anonymous. (2010). The Five Boons of Life. Flashfiction online.

Chavez, K. (2020). The Five Boons of LIfe.Western Governors University.

Cherry, K. (2020). How Freud's Pleasure Principle Works. 8 May 2020. very well mind. Ed.

Daniels, A. (2009). The Five Boons of Life by Mark Twain. Knoxville.

Dumitrescu, C. (2020).Freudian defence mechanisms. Univeristy Research

J. Zucker, k. (1979). Freud's Early Views on Masturbation and the Actual Neuroses.

The Journal of the American Academy of Psychoanalysis.

Ken, G. (2009). Freud and Nietzsche on Sublimation. The Journal of Nietzsche Studies.

Lapsley, K. Daniel, P.Stey, C. (2011). Id, Ego, and Superego. Encyclopedia of Human Behavior.

Liang, Y. (2011). The Id, Ego and Super-ego in Pride and Prejudice. International Education Studies.

Norman, R. (2016). Super-ego and the neuroscience of empathy: from unconscious wish to manifest behavior - a new human model." Mind Magazine.

Shereen, L. (2020). <https://www.verywellmind.com/what-is-thepleasure-principle-2795472>.

Sibi, K J.(2020). Sigmund Freud and psychoanalytic theory. langlit: an international peer-reviewed open access journal.

Siegfried, W. (2014). The Formation and Structure of the Human Psyche.Undergraduate Philosophy Journal.

Swati. (2020, December 10). The Five Boons of Life: Summary and Plot Analysis. Retrieved August 01, 2021, from Friends of Words : https://friendsofwords.com/2020/12/10/the- five-boons-of-lifemark-twain-summary-analysis-review/

Twain, M. (1885). The adventures of Huckleberry Finn. Glassbook Classics.

Zarnigor, S. (2019) The Realistic Genre and its Development in World Literature.International Journal of Recent Technology and Engineering. 